\title{
EXPERIMENTAL INVESTIGATION ON SOME PARAMETERS OF RICE STRAW ASH - FLY ASH GEOPOLYMER MORTAR.
}

\author{
M. I. Morsy ${ }^{1}$ and H. H. Mohamed ${ }^{2}$
}

\begin{abstract}
Concrete is one of the main materials in the construction industry. The Ordinary Portland Cement (OPC) concrete is vastly used as the main binder in construction industry which leads to depletion of natural resources in order to manufacture large quantities of $O P C$. Environmental hazards result from OPC production have become a major concern today. Nevertheless, Geopolymer concrete production $(G C)$ is a new environment friendly construction material, due to less emission of carbon dioxide. An experimental study on some engineering properties of Geopolymer Mortar (GM) prepared using the fly ash (FA) and rice straw ash (RSA) is presented in this research. FA was replaced with RSA by $0,5,10,15,20$, and $25 \%$ where the sodium silicate and sodium hydroxide were used as alkaline activator. The casted GM was divided in two main groups to study the effect of curing temperature. The first group was cured at room temperature for 28 days. The second group was cured at $80^{\circ} \mathrm{C}$ for 24 hours in an oven curing tank then in room temperature for 27 days. The test results show that compression strength and flexural strength of geopolymer mortar increase when the percentage of RSA increases up to 5\% replacement. The geopolymer materials exhibited strength increases after temperature exposure for 28 day.
\end{abstract}

Keywords: Geopolymer Mortar, fly ash, Rice Straw Ash, Compressive and flexural strength.

\section{INTRODUCTION}

$\mathrm{P}$ roduction of Portland cement consumes a large amount of energy and emits a substantial volume of $\mathrm{CO}_{2}$ to the atmosphere, causing a greenhouse effect and global warming. The production of one ton of Portland cement emits approximately one ton of $\mathrm{CO}_{2}$ into the atmosphere (Worrell et al. 2001).

1- Lecturer, Agric. \& Biosystems Eng. Dept., Fac. of Agric. El-Shatby, Alexandria University, Egypt.

2- Lecturer, Soil \& Ag. Eng. Dept., Fac of Agric. Saba Basha, Alexandria University, Egypt. 
However, Portland cement has been used as the main binding material in concrete manufacture particularly in developing countries, which promotes a task of searching for more environmentally safe materials such as fly ash, silica fumes, granulated blast furnace slag, rice husk ash and met kaolin in order to decrease the global warming.

Geopolymer mortars have attracted the attention of researchers to such materials as a potential replacement of portland-cement based concrete. These materials are produced by alkali activation of silica and aluminarich materials using alkaline activators such as sodium silicate or sodium hydroxide solutions (Li et al. 2004).

The schematic formation of geopolymer material can be shown by the following equations:

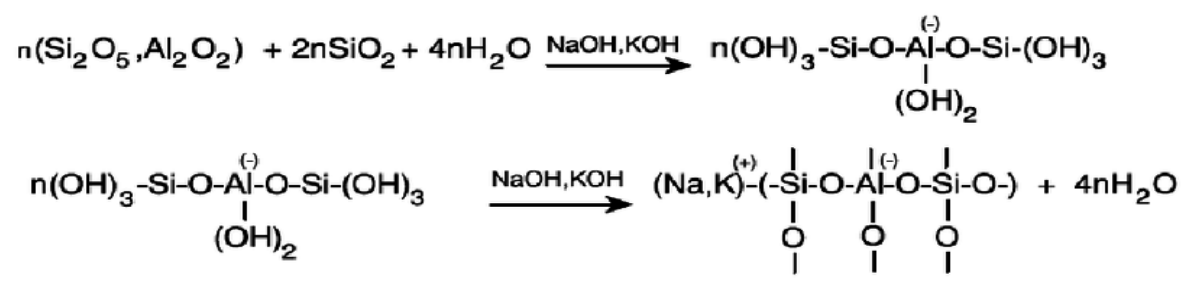

Davidovits (1994) reported that the geopolymeric materials have a wide range of applications such as in tire manufacture, civil engineering and plastic industries. The type of application of geopolymeric materials depends on the chemical structure and the atomic ratio ( $\mathrm{Si}: \mathrm{Al})$. The low ratio of $\mathrm{Si}$ : $\mathrm{Al}$ of 1,2, or 3 can be used to make drainage network that is very rigid, while $(\mathrm{Si}: \mathrm{Al})$ ratio higher than 15 provides a polymeric characteristic similar to the geopolymeric material.

Foaud and Abdelradi (2016) reported that rice production is the main source of secondary residues from rice straw, estimated at 4.5 million tons during the period 2003 to 2013, the area of cultivated rice crop in Egypt was 1.5 million feddan during the same period. Rice straw in Egypt is considered to be the field residue that is used partly for animal feed, mushroom farming, and bio-fuel production. Straw is stored on rooftops, making it a source of pollution and fire.

Rice straw is an agricultural waste that makes a lot of problems if not properly used like field burning, which increases air pollution and methane emission (Yuan et al. 2014).

This last process has a potent environmental effect in terms of greenhouse gas emission, as the global warming potential of methane is much higher than that of $\mathrm{CO}_{2} 25$-times (IPCC, 2007). 
The chemical properties of the fly ash are largely influenced by the chemical content of the coal burning (ASTM C618, 2008).

Piyaphanuwat and Asavapisit (2009) reported that the durability of geopolymer concrete increases by increasing RSA in concrete. On the other hand an additional source of aluminum is needed because RSA contains very little aluminum. This research was carried out to:

1) Evaluate the effect of replacing fly ash by rice straw ash on the mechanical and physical properties of the geopolymer mortar.

2) Evaluate the effect of curing temperature on the physical and the mechanical properties of geopolymer mortars.

\section{MATERIALS AND METHODS}

In this study fly ash (FA) and rice straw ash (RSA) were used as main components for manufacturing geopolymer mortar. FA was kept as the base material, while RSA was added in different percentages to study the changes in the mechanical properties (compressive and flexural strengths) and Physical properties (workability, density, porosity, and water absorption).

\subsection{Materials:}

Geopolymer mortar is formed of the following materials:

\subsubsection{Fly ash (FA)}

Fly ash (FA) is a by-product of the combustion of powdered coal or other materials in thermal power plants. It is a fine grained, powdery and glassy particulate material that is collected from the exhaust gases by electrostatic separation or by filters. When pulverized coal is burnt to generate heat, the residue contains $80 \%$ fly ash and $20 \%$ bottom ash. The fly ash is a main source of alumina. Fly ash color is light gray as shown in Fig. (1). It was obtained from Sika Egypt Factory. There are two classes of fly ash; class $\mathrm{F}$ and class $\mathrm{C}$. The main difference between the two classes is the amounts of calcium, silica, alumina and iron contained by the fly ash.

\subsubsection{Rice straw ash (RSA)}

Rice straw ash (RSA) is an agriculture waste generated by burning rice straw in incinerator. It is considered the main source of silica. It has a high content of silica (87-97\%), which can be used as a building material (Li et al. 2004). An additional source of Aluminum is required since RSA contains very little amount of alumina. 
In this study, rice straw ash was obtained by burning the rice straw in an earthen oven, used by the rural people under uncontrolled combustion process. Burning temperatures are usually in the range of 600 to $700^{\circ} \mathrm{C}$ (Kalapathy et al., 2002). The RSA color is dark gray as shown in Fig. (2).

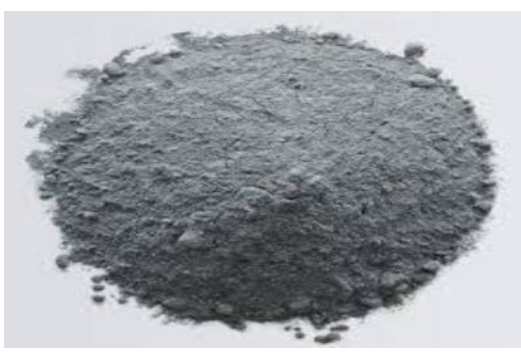

Fig. (1). Sample of FA.

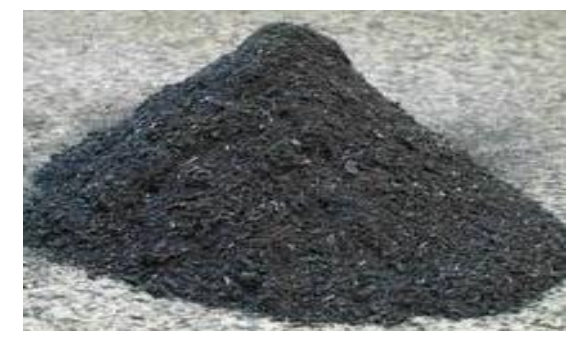

Fig. (2). Sample of RSA.

\subsubsection{Natural sand (fine aggregate)}

Natural sand was used as a fine aggregate with fineness modulus of 2.25 and specific gravity of $2.58 \mathrm{~g} / \mathrm{cm}^{3}$.

\subsubsection{Tab water}

A clean and free from any visible impurities tap water was used in this study.

\subsubsection{Alkaline solution}

The used alkaline solution was a combination of sodium silicate and sodium hydroxide which were purchased from a local supplier. The sodium silicate solution consists of $13.7 \% \mathrm{Na}_{2} \mathrm{O}, 29.4 \% \mathrm{SiO}_{2}$ and $55.9 \%$ tap water by mass. The sodium hydroxide $(\mathrm{NaOH})$, in flakes or pellets, was $97-98 \%$ purity. The sodium hydroxide $(\mathrm{NaOH})$ solution was prepared by dissolving the flakes or the pellets in water. The mass of $\mathrm{NaOH}$ solids added in a solution varied depending on the concentration of the solution expressed in terms of molar (M). For instance, $\mathrm{NaOH}$ solution with a concentration of $10 \mathrm{M}$ consisted of $10 \mathrm{x} 40=400$ grams of $\mathrm{NaOH}$ solids per liter of water, where 40 is the molecular weight of $\mathrm{NaOH}$. The molar concentration of sodium hydroxide was kept as $10 \mathrm{M}$. The ratio of sodium silicate to sodium hydroxide in the alkaline solution was 2.5: 1 (ASTM C618, 2008).

\subsection{Methodology :}

In this research class $\mathrm{F}$ fly ash (FA) and rice straw ash (RSA) were used as the main components for manufacturing geopolymer mortar. 


\subsubsection{Chemical analysis of FA and RSA}

The chemical compositions of FA and RSA were determined by using Xray fluorescence technique as presented in Table (1).

The total percentages of oxides in FA and RSA were 84.61 and $75.4 \%$ respectively. These values are higher than the minimum required value of 70\% for using pozzolanas (ASTM C618, 1993).

There is a slight difference in the percentage of composition between FA and RSA, which is due to the method of ash preparation. The Rice Straw Ash loss in ignition was about $8.5 \%$. This value is within the allowed value of $12 \%$ as a maximum percentage required for using pozzolanas. It means that the RSA contains little unburnt carbon. The unburnt carbon is not pozzolanic material and can be used as a filler to the mixture.

Table 1: Elemental composition (weight \%) of fly ash and rice straw ash used in this study, determined by $\mathrm{X}$-ray fluorescence.

\begin{tabular}{ccccccccccc}
\hline $\begin{array}{c}\text { Constituent } \\
\text { Composition,\% }\end{array}$ & $\mathrm{Fe}_{2} \mathrm{O}_{3}$ & $\mathrm{SiO}_{2}$ & $\mathrm{CaO}$ & $\mathrm{Al}_{2} \mathbf{O}_{3}$ & $\mathbf{M g O}$ & $\mathrm{K}_{2} \mathbf{0}$ & $\mathbf{N a 0}$ & $\mathrm{So3}$ & L.0.I \\
\hline Fly Ash & 5.23 & 48.72 & 6.5 & 30.66 & 1.1 & 1.02 & 0.45 & 0.88 & 5.41 \\
\hline Rice Straw Ash & 0.90 & 69.20 & 3.46 & 5.30 & 2.81 & 6.40 & 3.43 & 0 & 8.50 \\
\hline
\end{tabular}

\subsubsection{Physical properties of FA and RSA}

The true densities of RSA and FA were 2.13 and $2.29 \mathrm{~g} / \mathrm{cm}^{3}$ respectively, as determined by helium pycnometer, which are less than the density of cement $\left(3.15 \mathrm{~g} / \mathrm{cm}^{3}\right)$, meaning that both materials are light weight materials.

\subsubsection{Sieve analysis of FA and RSA}

The particle size analysis of FA and RSA was done by using a set of sieves $300,150,90$, and $75 \mu \mathrm{m}$ sieves. The set of sieves was placed on a shaker for 15 minutes. The weights of ashes retained on each sieve were measured. The sieve analysis results are shown in Fig. (3).

\subsection{Composition of geopolymer mortar:}

The geopolymer mortar was formed of fly ash (FA), rice straw ash (RSA), sand and water in a mix of 1000 grams.

The used mixture proportions of geopolymer mortars are shown in Table (2). 


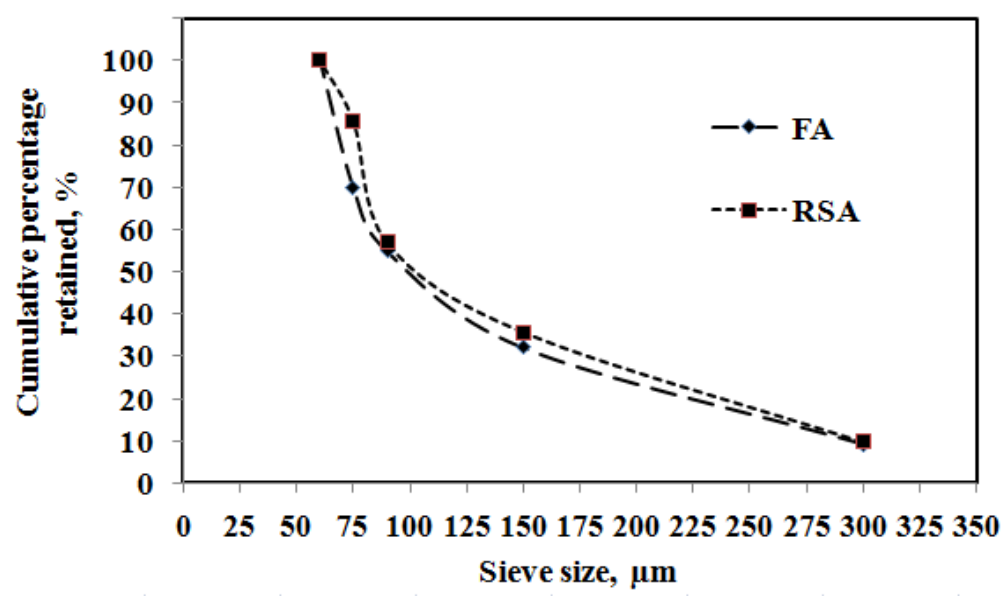

Fig. (3) Fly ash and rice straw ash particle size analysis.

Batching of materials was done by weight. The replacements percentage of FA by RSA were $0,5,10,15,20$ and $25 \%$. The zero percent of RSA was considered a reference sample to the other samples. The FA- RSA binders were mixed with sand at a ratio of $1: 3$ by weight. The ratio of alkaline solution to the binder ratio was taken to be 0.50 . The ratio of water to binder $(\mathrm{w} / \mathrm{b})$ ranged from 0.50 at $(\mathrm{RSA}=0 \%)$ to 0.6 at $(\mathrm{RSA}=$ $25 \%)$ as given in table (2).

Table 2: Mixture proportions of FA-RSA geopolymer mortars.

\begin{tabular}{ccccc}
\hline Experiment & FA, g & RSA, g & Sand, g & W/B Ratio \\
\hline 100\% FA, 0 \% RSA & 1000 & 0 & & 0.50 \\
95 \% FA, 5 \% RSA & 950 & 50 & & 0.52 \\
90 \% FA, 10\% RSA & 900 & 100 & 3000 & 0.54 \\
85 \% FA, 15\% RSA & 850 & 150 & & 0.56 \\
80 \% FA, 20\% RSA & 800 & 200 & & 0.58 \\
$75 \%$ FA, 25\% RSA & 750 & 250 & & 0.60 \\
\hline
\end{tabular}

\subsection{Experimental procedures}

\subsubsection{Preparation of test specimen}

A- The materials for the used mixture were weighed and mixed in dry condition for 3-4 minutes.

B- The alkaline solution and the super-plasticizer, were added to the dry mix.

C- Extra water of about $r \cdot \%$ of the binder weight was added to improve the workability. 
D- Mixing process was continued for about 6-8 minutes. The obtained geopolymer mortar was poured in a $(40 \times 40 \times 160 \mathrm{~mm})$ mold as shown in Fig. (4).

E- One half of the specimens was left at room temperature for the first 24 hours, while the second half was left in the oven at $80{ }^{\circ} \mathrm{C}$ for 24 hours. F- The specimens were removed from their moulds.

G- The specimens were cured at room temperature.

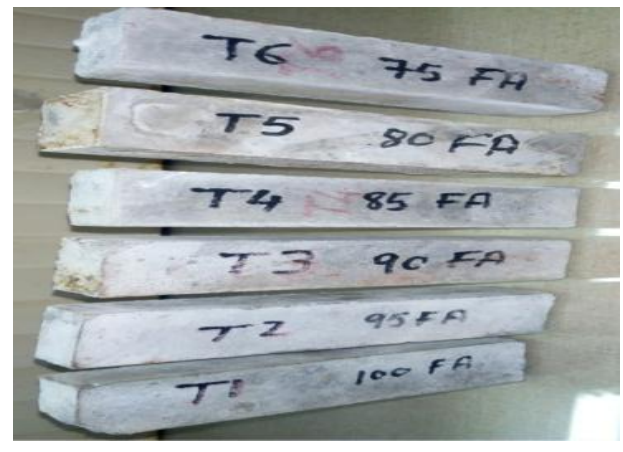

Fig. 4. Casted presumes samples.

\subsubsection{Mechanical tests}

\section{A. Compressive strength}

The compressive strength of the geopolymer mortar was tested according to European Standard (DIN EN 196-1). A servo hydraulic material testing system with a maximum capacity of $100 \mathrm{kN}$ was used to apply a constant loading rate test of $140 \mathrm{~kg} / \mathrm{cm}^{2}$ per min until failure. The testing machine was located in the lab of testing materials, Faculty of Engineering, Alexandria University, as shown in Fig. (5.a). A cubic specimen of $40 \mathrm{~mm}$ dimension was used for each test. Three replicates of compressive strength tests were applied on specimens of different RSA contents as given in table (2). The tests were conducted after one day, 7 days and 28 days of removing the specimen from the mold. The compressive strength (CS) was calculated as follows:

$$
\mathrm{CS}=\frac{\mathrm{Fu}}{\mathrm{W}^{2}}
$$

Where:

CS: Compression stress, MPa. $\quad$ Fu: Ultimate load, N.

W: Width of sample, mm. 


\section{B. Flexural strength}

The flexural strength of the geopolymer mortar was carried out by the European standard (DIN EN 196-1) using a Universal Testing Machine as shown in Fig. (5b). Beams of dimensions $40 \times 40 \times 160 \mathrm{~mm}$ were cast and then subjected to the three point Flexural test. Maximum load was measured to calculate Flexural strength after 28 days using the following formula for three point bending test:

$$
\mathrm{FS}=\frac{3 \mathrm{PL}}{2 \mathrm{BD}^{2}}
$$

Where:

FS: Flexural strength, MPa.

L: Length of the sample, $\mathrm{mm}$.

D: Thickness of the sample, mm.

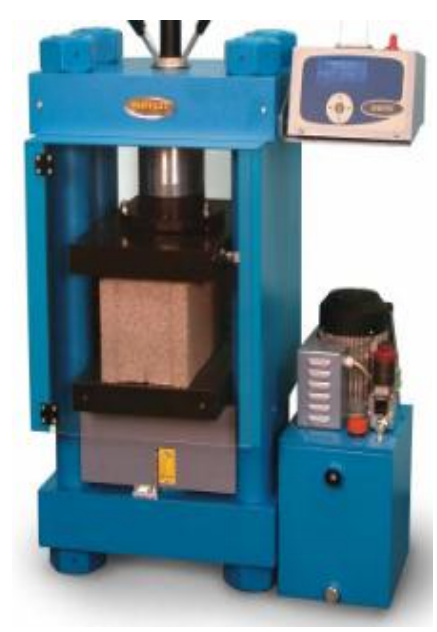

Fig. (5). a: Compressive test machine.
P: Maximum load, N.

B: Width of the sample, $\mathrm{mm}$.

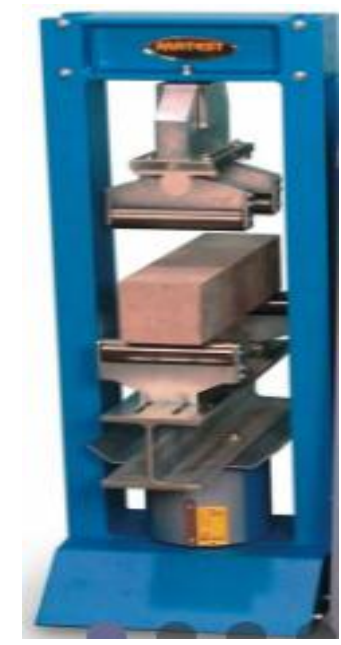

b: Flexural test machine.

\subsubsection{Physical properties}

\section{A. Bulk density}

For determination of hardened composite bulk density, a set of samples, each of dimensions $4 \times 4 \times 16 \mathrm{~cm}$ were tested. Three replicates of each sample were tested after 28 days from removing from the mold. All samples were dried at $105 \pm 5^{\circ} \mathrm{C}$ until a constant weight was achieved and then was placed in the air to cool down.

The weight and the volume of each dried specimen were measured. The bulk density was determined as follows: 


$$
\rho_{b}=\frac{\mathbf{W}_{\mathbf{d}}}{\mathbf{V}}
$$

Where:

$\boldsymbol{\rho}_{b}$ : Bulk density of the sample, $\mathrm{g} / \mathrm{cm}^{3} . \quad \mathbf{W}_{\mathbf{d}}$ : Weight of dry sample, $\mathrm{g}$. $\mathbf{V}$ : Volume of the sample, $\mathrm{cm}^{3}$.

\section{B. Water absorption and Porosity test}

Three replicates were used for each test after 28 days. All samples were dried at $105 \pm 5^{\circ} \mathrm{C}$ until a constant weight was achieved. Water absorption was determined according to the American Standard Testing Method ASTM (D-1037) as follow: the dried specimens were weighed to the nearest 0.01 gram. The tested specimens were then soaked in water at the room temperature for 24 hours. The specimens were hanged to drain the water for 10 minutes and the excess surface water was wiped. The specimen was weighed to the nearest 0.01 gram. The amount of water absorbed after 24 hours of soaking was calculated as a percentage of the original weight of test specimens.

$$
\mathrm{W}=\left(\frac{\mathrm{W}_{\mathrm{a}}-\mathrm{W}_{\mathrm{d}}}{\mathrm{W}_{\mathrm{d}}}\right) \times 100
$$

Where:

W : Water absorption, \%. Wa : Weight of saturated sample in air, g. Wd : Specimen dry weight, g.

The porosity was also calculated after 7 days of soaking in water, using a method that has been used for measuring cement-based materials porosity successfully (Gonen and Yazicioglu, 2007). , as follows:

$$
\mathrm{P}=\frac{\mathrm{W}_{\mathrm{a}}-\mathrm{W}_{\mathrm{d}}}{\mathrm{W}_{\mathrm{a}}-\mathrm{W}_{\mathrm{w}}} \times 100
$$

Where:

Ww : Specimen weight in water, g. $\quad$ P : Saturated porosity, $\%$.

\section{RESULTS AND DISCUSSION}

\subsection{Physical properties of geopolymer mortars}

\subsubsection{Bulk density and total porosity:}

The Bulk density of the FA - RSA mortars after 28 days of curing for heated and unheated specimens are illustrated in Fig.( 7 ). The results showed that, the bulk density slightly increases with the increase of RSA 
at the first step from 0 to 5\% RSA this could be attributed to the particle space filler effect by RSA particles. On the other hand the bulk density decreases at the second step from 5 to $25 \%$ RSA, which could be due to the increase in voids in the mortars matrix as the percentage of RSA increases. The maximum value of bulk density was about $2.265 \mathrm{~g} / \mathrm{cm}^{3}$ for heated and unheated specimens at RSA 5\%. The minimum value of bulk density was about $1.92 \mathrm{~g} / \mathrm{cm}^{3}$ for heated and unheated specimens at RSA $25 \%$.

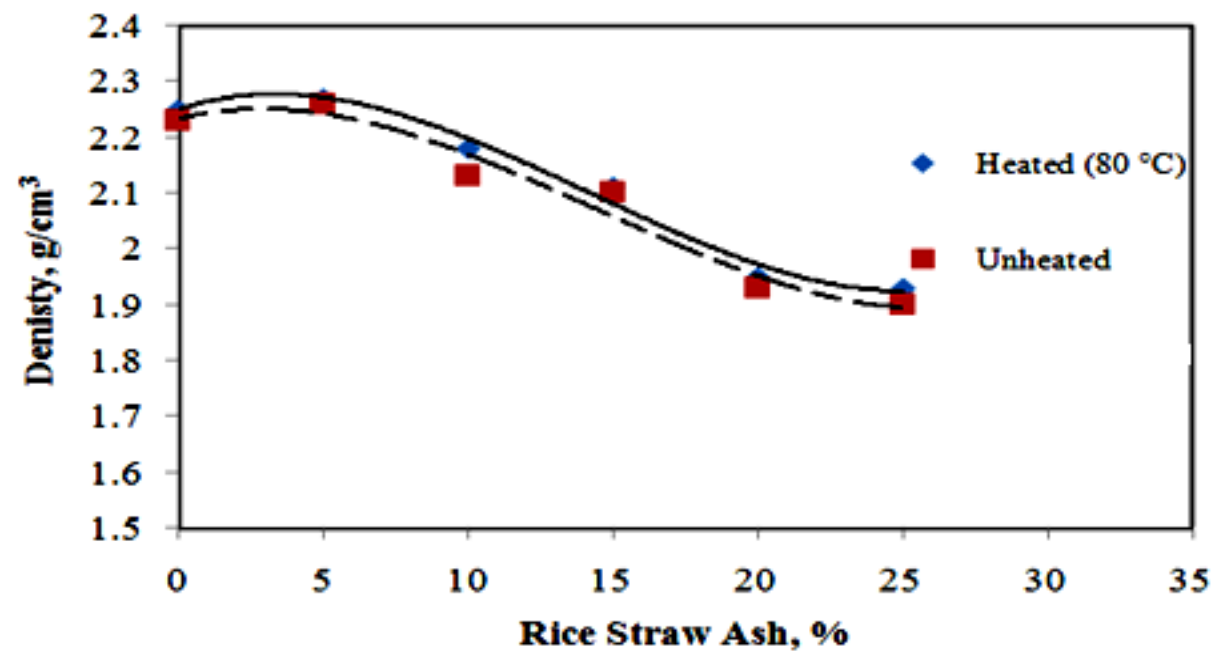

Fig. (6). Effect of RSA, \% on the Bulk density of RSA-FA hardened mortars at 28 day.

The effect of RSA content on the total porosity of hardened mortars is shown in Fig. ( $\vee$ ). In general the results showed that, the porosity decreases with the increase of RSA at the first step from 0 to 5\% RSA this could be attributed to the change occurring in the pore size distribution as a result of changing the Si/Al ratio, which could produce more geopolymer gel. On the other hand, the total porosity increases at the second step from 5 to $25 \%$ RSA, this could be due to increase the amount of voids in the matrix, because RSA particles had micro porous surface than FA particles. The maximum value of porosity was 12.4 and $13.4 \%$ for heated and unheated specimens respectively at RSA $25 \%$. The minimum value of porosity was 9.8 and $10.4 \%$ for heated and unheated specimens respectively at RSA $5 \%$. There is a clear compatibility between the bulk density and porosity, which makes sense. 


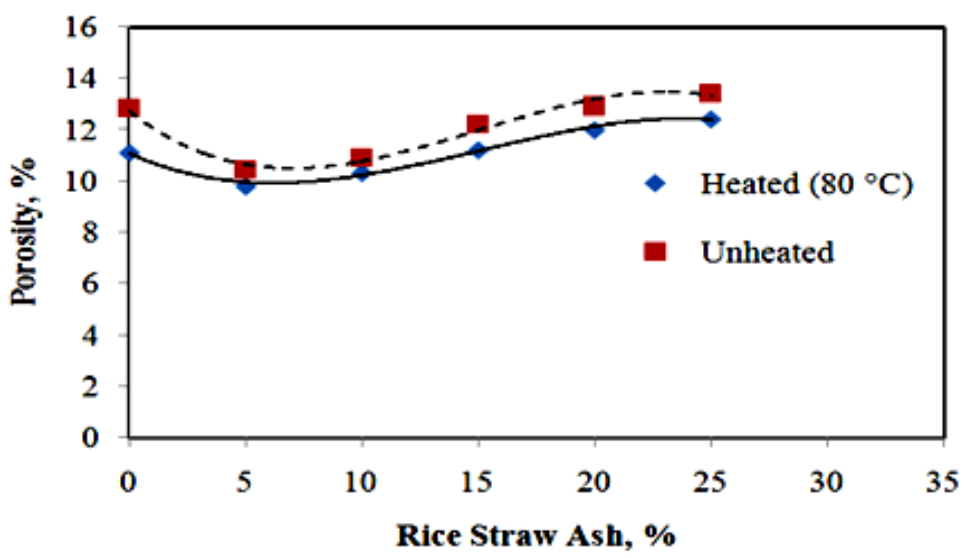

Fig. (7). Effect of RSA, \% on the porosity, \% of hardened mortars at 28 day.

\subsubsection{Water absorption of FA-RSA mortars:}

The effect of RSA content on the water absorption of hardened mortars at 28 day of hydration for heated and unheated specimens are shown in Fig. (^). In general the results showed that, the water absorption decreases with the increase of RSA at the first step from 0 to 5\% RSA. On the other hand the water absorption increases at the second step from 5 to $25 \%$ RSA, this could be due to the reduction in total porosity which occurs as shown in Fig. $\left({ }^{\vee}\right)$. Then the more RSA content, the more water absorption. Also, this agrees with the density and porosity results. The maximum value of water absorption was 8 and $9.2 \%$ for heated and unheated specimens respectively at RSA $25 \%$. The minimum value of water absorption was 5.4 and $6.3 \%$ for heated and unheated specimens respectively at RSA $5 \%$.

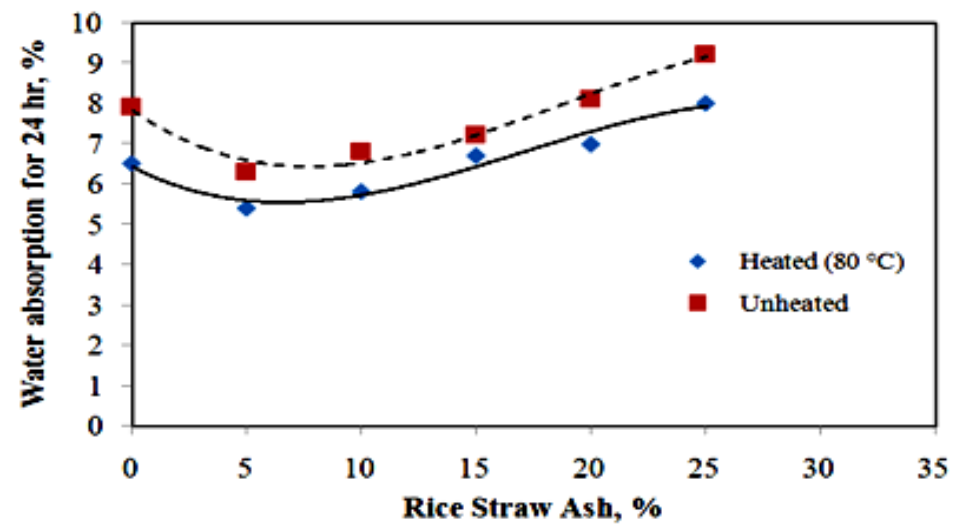

Fig. (8). Effect of RSA, \% on the water absorption of hardened mortars at 28 day, $\%$. 


\subsection{Mechanical properties of FA-RSA mortars}

\subsubsection{Compressive strength (CS)}

The results of the compressive strength (CS) of FA hardened mortars with $5,10,15,20$ and $25 \%$ RSA at 1, 7 and 28 day are presented in Table (4) and Figs (9, 10 and 11).

In general the results showed that, the compressive strength (CS) for all tested hardened mortars increases with the increase of RSA from 0 to $5 \%$ RSA, while resulted in decreases from 5 to $25 \%$ RSA.

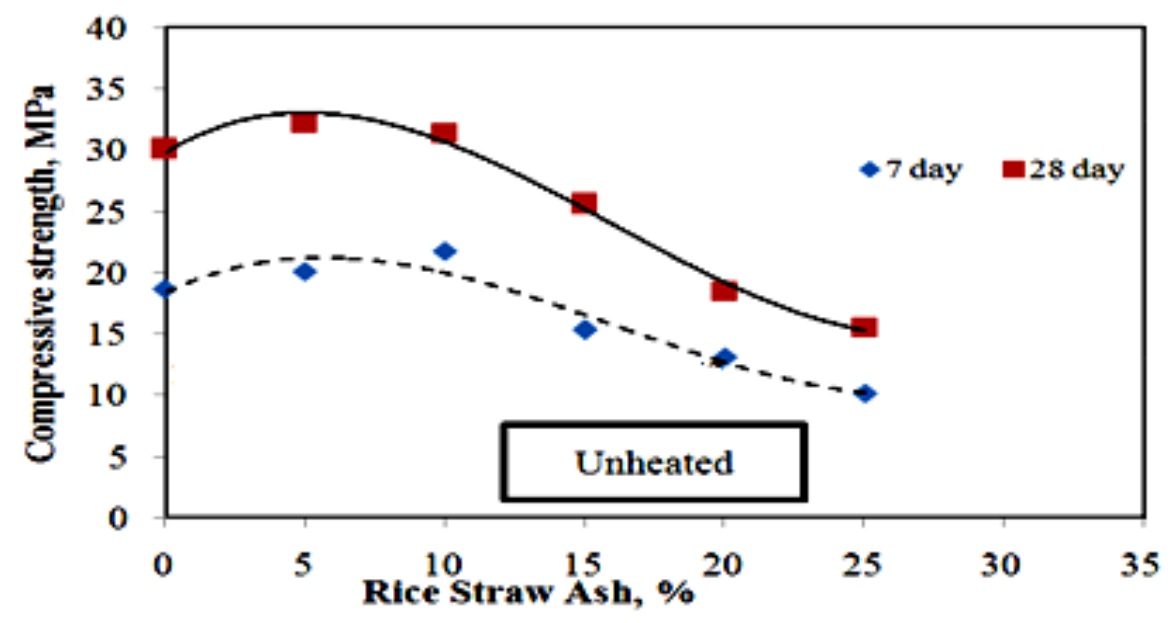

Fig. (9). Effect of RSA, \% on compressive strength for unheated mortars samples.

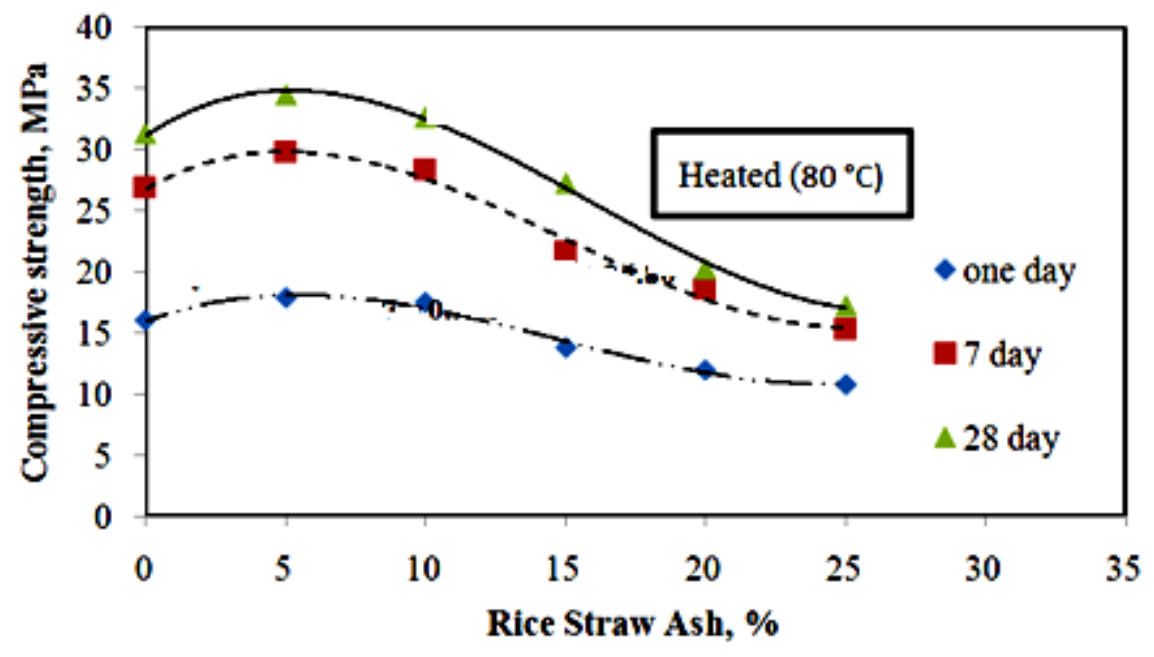

Fig. (10). Effect of RSA, \% on compressive strength for heated mortars samples. 
The maximum values of compressive strength (CS) were 34.5 and 32.2 MPa for heated and unheated samples respectively at RSA 5\% after 28 days of curing, while the minimum values were 15.3 and 10.2 MPa for heated and unheated specimens respectively at RSA $25 \%$ after 7 days of curing. It was observed a continuous increase in the compressive strength with curing time, also the compressive strength for heated samples was higher than unheated samples as shown in Fig.(11), which is due to the increase in the speed of geopolymer reacting by heating process as reported by (Fernandez et al. 2003).
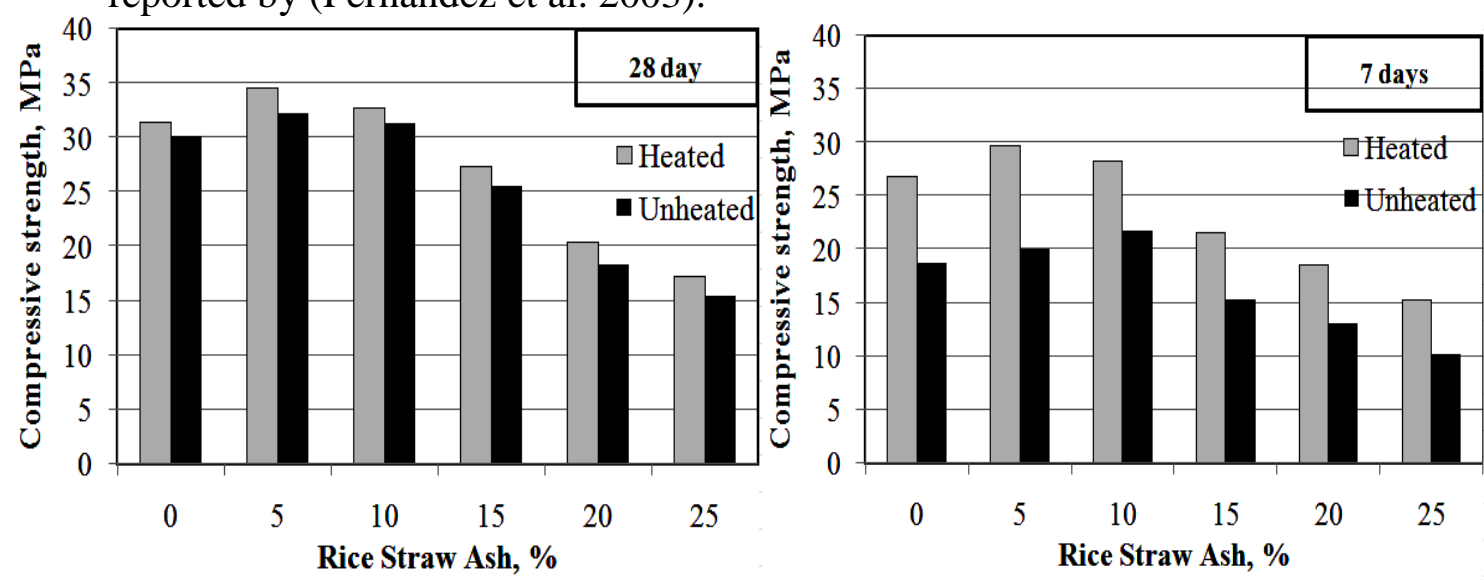

Fig. (11). Effect of RSA, \% on compressive strength for heated and unheated mortars samples.

Table (3): Compressive strength values for FA-RSA mortars.

\begin{tabular}{|c|c|c|c|c|c|}
\hline \multirow{3}{*}{ Rice straw ash, \% } & \multicolumn{5}{|c|}{ Compressive strength, $\mathrm{MPa}$} \\
\hline & \multicolumn{3}{|c|}{ Heated } & \multicolumn{2}{|c|}{ Unheated } \\
\hline & $24 \mathrm{hr}$ & 7 day & 28 day & 7 day & 28 day \\
\hline $\mathbf{0}$ & 16 & 26.8 & 31.3 & 18.7 & 30.1 \\
\hline 5 & 17.9 & 29.7 & 34.5 & 20.1 & 32.2 \\
\hline 10 & 17.5 & 28.3 & 32.6 & 21.8 & 31.3 \\
\hline 15 & 13.8 & 21.6 & 27.3 & 15.3 & 25.6 \\
\hline 20 & 12 & 18.5 & 20.3 & 13.1 & 18.4 \\
\hline 25 & 10.8 & 15.3 & 17.2 & 10.2 & 15.5 \\
\hline
\end{tabular}

\subsubsection{Flexural strength}

The results of the flexural strength of FA hardened mortars with $0,5,10$, 15, 20 and $25 \%$ RSA at 28 day for heated and unheated samples are presented in Fig.(12). It is obvious that the flexural strength follows the same pattern as the compressive strength. The flexural strength of FA- 
RSA mortars increases gradually by replacing FA with RSA up to 5\% and then decreases from 5 to $25 \%$ RSA, which is due to the high formation of gel than control mortar without RSA. This is in agreement with CS results.

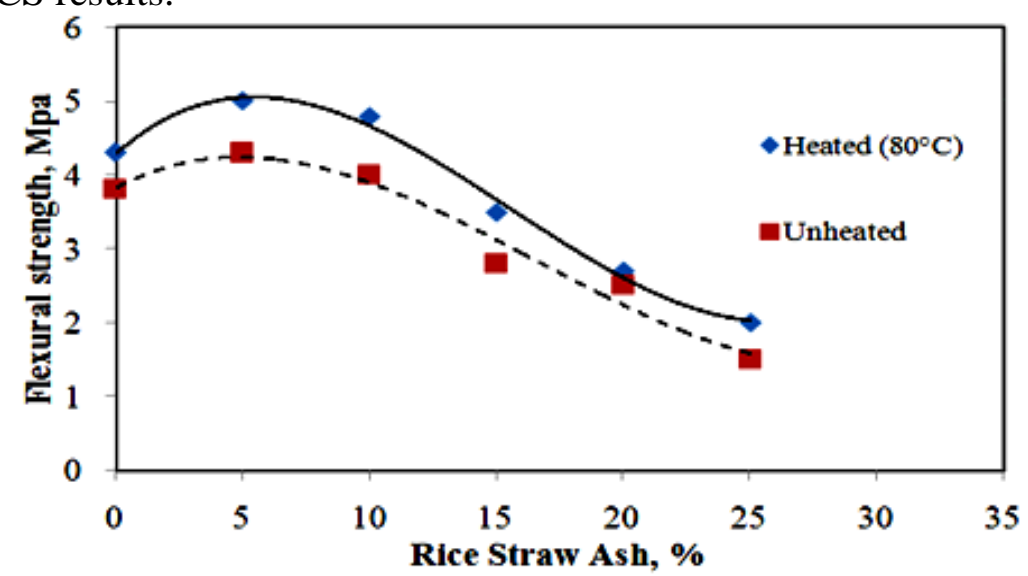

Fig. (12). Effect of RSA, \% on Flexural strength for heated and unheated mortars at 28 day samples.

The maximum values of flexural strength (FS) were 5 and $4.3 \mathrm{MPa}$ for heated and unheated samples respectively at RSA 5\% after 28 days of curing, while the minimum values were 1.5 and $2 \mathrm{MPa}$ for heated and unheated specimens respectively at RSA $25 \%$ after 7 days of curing. The flexural strength of heated samples was higher than unheated samples, which is due to increase the speed of geopolymer reacting by heating process as reported by (Fernandez et al. 2003).

\section{CONCLUSIONS}

This study presents the effect of curing temperature and time on the physical and the mechanical properties of geopolymer mortars using pozzolanic materials (FA and RSA). FA was replaced with RSA by 0,5 , $10,15,20$, and $25 \%$ where the sodium silicate and sodium hydroxide was used as alkaline activator.

The test results show that the compression strength and the flexural strength of geopolymer mortar increases when the percentage of RSA increases up to $5 \%$ replacement. The maximum values of bulk density, compressive strength (CS) and flexural strength (FS) were $2.27 \mathrm{~g} / \mathrm{cm} 3$, 34.5 MPa and 5 MPa for heated specimens respectively, while were 2.26 $\mathrm{g} / \mathrm{cm} 3,32.2 \mathrm{MPa}$ and 4.3 $\mathrm{MPa}$ for unheated specimens respectively at RSA $5 \%$. The maximum values of porosity and water absorption were 
$12.4 \%$ and $8 \%$ at RSA $25 \%$ for heated specimens respectively, while were $13.4 \%$ and $9.2 \%$ for unheated specimens respectively.

A continuous increase in the compressive strength occurs with curing time, also the compressive strength and flexural strength for heated samples were higher than unheated samples.

The results showed that the porous geopolymers exhibited strength increases after temperature exposure for 28 day.

The results of the compressive strength and flexural strength indicated that the best mixture is $90 \% \mathrm{FA}$ and $10 \%$ RSA, which can be use as a natural binder instead of using cement.

\section{REFERENCES}

ASTM C618. Standard specification for coal fly ash and raw or calcined natural pozzolan for use as a mineral admixture in concrete. Annual Book of ASTM Standards. Philadelphia, USA; 1993.

ASTM C618 - 08. Standard Specification for Coal Fly Ash and Raw or Calcined Natural Pozzolan for Use in Concrete. ASTM International. Retrieved 2008-09-18.

Davidovits, J., 1994. High-Alkali Cements for 21st Century Concretes. Concrete Technology, Past, Present and Future. 144, pp.383-397.

Fernandez-Jimenez, A. and A. Palomo, 2003. Characterisation of fly ashes Potential reactivity as alkaline cements. Fuel.;82: 2259-2265.

Foaud، A. A. and F. Abdelradi, 2016. Analysis of the Rice Straw Recycling Value Added in Egypt Agricultural Economics. J. Agric. Econom. and Social Sci., Mansoura Univ., Vol. (11): 1039 - 1045.

Gonen, T. and S. Yazicioglu, (2007). The influence of mineral admixtures on the short and long-term performance of concrete. Building and Environment, 42: 3080-3085.

IPCC, 2007. International Panel on Climate Change. Climate Change. The Physical Science Basis. Cambridge University Press, Cambridge.

Kalapathy, U., A. Proctor and J. Shultz, 2002. An improved method for production of silica from rice hull ash, Bioresour.Techn. 285-289.

Li, Z.; Z. Ding, and Y. Zhang, 2004. Development of sustainable cementations materials. International workshop on sustainable development and concrete technology, Beijing, China, pp. 55-76. 
Piyaphanuwat, R. and S. Asavapisit, 2009. Effect of Black Rice Husk Ash Substituted OPC on Strength and Leaching of Solidified Plating Sludge, Journal of Metals, Materials and Minerals, Vol.19 No. 2, pp. 85-89.

Worrell, E.; L. Price, and L. Ozawa, 2001. Carbon Dioxide Emission from the Global Cement Industry . Annu. Rev. Energy Environ. 26:303-29.

Yuan, Q., J. Pump, and R. Conrad, 2014. Straw application in paddy soil enhances methane production also from other carbon sources. Biogeoscience 11, 237-246.

\section{الملخص العربى}

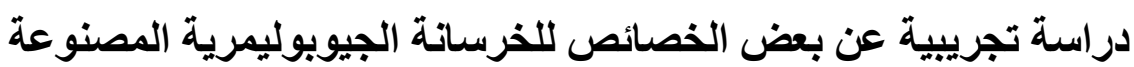
باستخدام الرماد المتطاير من الفحم و قش الأرز

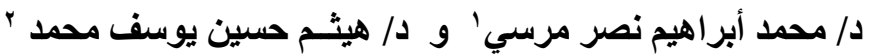

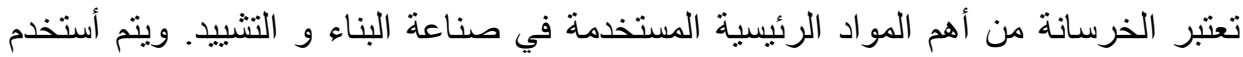

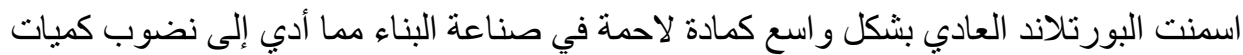

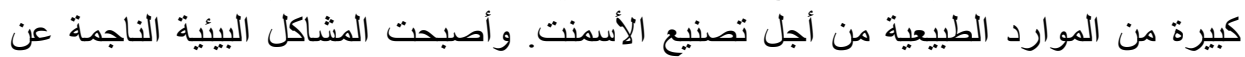

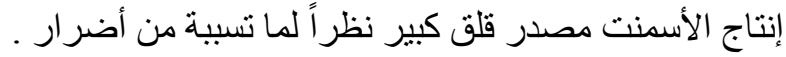

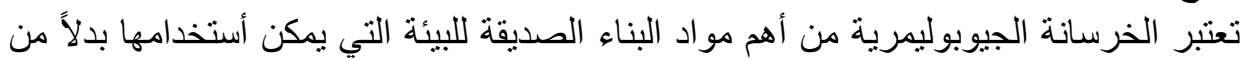

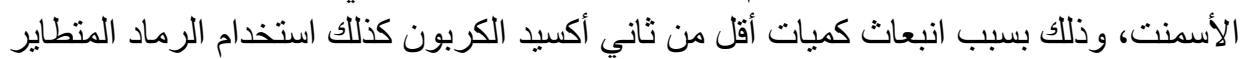

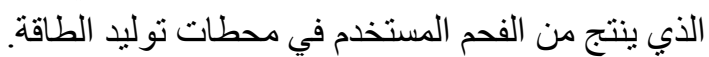

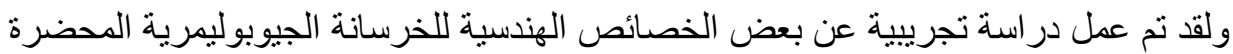

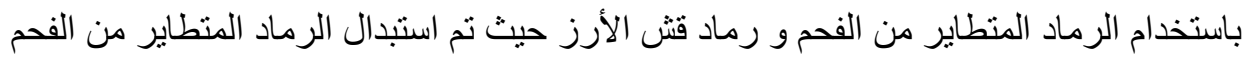

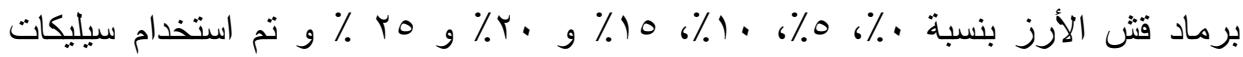

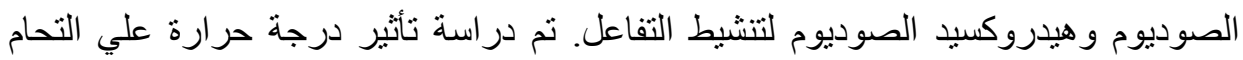

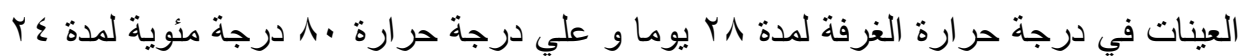

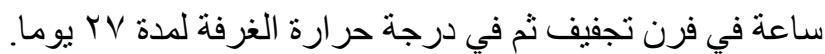

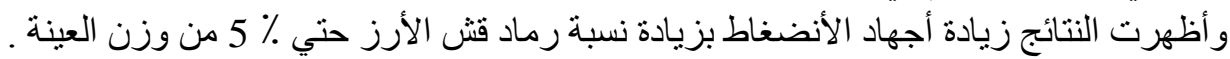

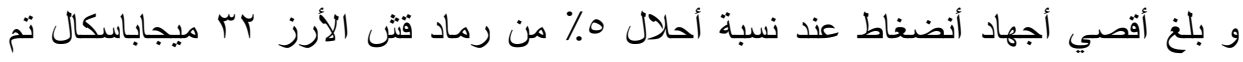

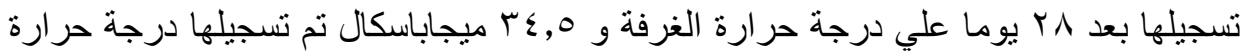

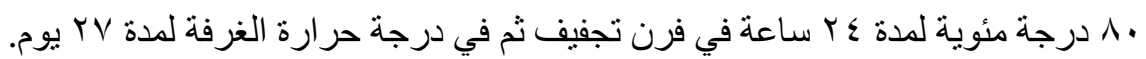

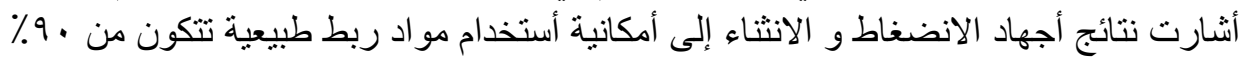
رماد منطاير من الفحم و • ( ٪ رماد قش الأرز بدلاً من استخدام الاسمنت.

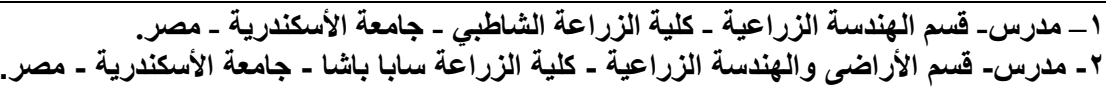

